Fabio Nelson Rodríguez Díaz*

\title{
Propuesta para la optimización de la interacción de los visitantes en el cibermuseo $^{1}$
}

\author{
Proposal for the optimization of the interaction of visitors \\ in the virtual museum
}

Cómo citar:

Rodríguez, F. (2017). Propuesta para la optimización de la interacción de los visitantes en el cibermuseo. Designia, 5(1), 31-47.

\author{
${ }^{1}$ El Cibermuseo, un medio para reconocer el patrimonio \\ urbano difuso de Tunja, es un proyecto desarrollado por \\ la Universidad de Boyacá y cofinanciado con recursos del \\ patrimonio autónomo, Fondo Nacional de Financiamiento \\ para la Ciencia, la Tecnología y la Innovación, \\ Francisco José de Caldas (Colciencias). \\ * Fabio Nelson Rodríguez Díaz, Magíster en Museología y \\ Gestión del Patrimonio y Diseñador gráfico, egresado de la \\ Universidad Nacional de Colombia. Profesor asistente en la \\ Universidad de Boyacá. Tunja, Boyacá, Colombia. \\ fnrodriguez@uniboyaca.edu.co \\ orcid.org/0000-0003-0652-4107
}

\section{Palabras clave:}

Museo, patrimonio cultural, presentación de bienes culturales, interfaz hombre máquina, usuario cultural.

\section{Key words:}

Museum, cultural heritage, cultural property presentation, human-machine interface, cultural user.

Recibido: $11 / 11 / 2016$ Aceptado: 10/02/2017

El presente artículo presenta los resultados del proyecto "El Cibermuseo, un medio para reconocer el patrimonio urbano difuso de Tunja", en lo concerniente al objetivo específico que busca "optimizar la interacción con los visitantes mediante la evaluación de las herramientas TIC y los ejercicios propuestos". Dicho análisis se construyó a partir de datos cualitativos y cuantitativos. En primer término, se analizaron las opiniones recogidas a través de la herramienta de recopilación de comentarios del sitio web del Museo y de los formularios de Google Drive que fueron diligenciados en el marco de los talleres realizados con el fin de conseguir interacciones de los usuarios. Igualmente, se evaluaron los datos estadísticos cuantitativos de visitas al sitio web, obtenidos por medio de la herramienta de Google 
Analytics. Las principales conclusiones y recomendaciones se presentan organizadas en tres grupos. 1) Optimización desde el proyecto: misión y objetivos de un museo. Se plantea la necesidad de establecer objetivos operativos y metodologías acordes al área de conocimiento de cada etapa del proyecto. 2) Optimización desde la comunicación: diseño centrado en el usuario. Se propone construir un mensaje y organizar la información disponible con claridad de rutas para un acceso eficaz. 3) Optimización visual y tecnológica. Se examinan elementos visuales y tecnológicos que permitan una cómoda interacción de los usuarios; se plantea la evaluación de los mismos y las metodologías y características del equipo de trabajo. A su vez, se expresa la necesidad de contar con personas con habilidades especializadas para las tareas requeridas, sin descuidar la construcción colectiva, el ejercicio transdisciplinar y el diálogo de saberes.

\section{Abstract:}

This article describes the results of the project "The virtual museum, a medium to recognize Tunja's urban unknown heritage", regarding its objective of "optimizing the interaction with visitors through the assessment of the ICT tools and the proposed exercises". Such an analysis is based in both qualitative and quantitative data. Visitor's opinions were collected through the Museum website's feedback tool and the Google Drive's forms submitted by users as part of workshops aimed to interact with them. Quantitative statistical data associated to visits to the website were obtained through the Google Analytics tool. This set of information was analysed. The conclusions and recommendations for the project's optimization are grouped around three axes: 1) mission and objectives of museums; 2) user-based design; 3) visual and technological elements for interaction with users. It is also stressed the relevance of co-creation and dialogue between knowledge from different disciplines. 


\title{
INTRODUCCIÓN
}

"El Cibermuseo, un medio para reconocer el patrimonio urbano difuso de Tunja", fue un proyecto cuyo objetivo principal apuntó a caracterizar la apropiación de elementos representativos del patrimonio urbano difuso de dicha ciudad a partir de la utilización de las Tecnologías de Información y Comunicación (TIC) en el Museo Urbano Territorial de los Andes Nororientales (Mutua). Tal objetivo se cumplió a cabalidad, pues se caracterizaron y reconocieron elementos del patrimonio de los tunjanos, al tiempo que se justificó a través de una juiciosa investigación su valor cultural y por qué debería existir un vínculo entre ellos y la comunidad.

\section{El primer objetivo específico del Cibermuseo buscó}

\begin{abstract}
el reconocimiento y la divulgación de testimonios y marcas referenciales inherentes a procesos urbanos e históricos registrados en la región centrooriental colombiana, que debido a su significado pueden considerarse como patrimonio aunque carecen de un amplio reconocimiento por parte de la ciudadanía y las autoridades. En efecto, mediante el empleo de las TIC, Mutua apunta a seleccionar algunos de esos referentes y reproducirlos en su plataforma de internet con el fin de otorgarles visibilidad, propiciar su estudio y diagnosticar su posible percepción por parte de las comunidades con las cuales interactúan. Esto último, a su vez, constituye una base aprovechable en eventuales programas oficiales o particulares de planeación e intervención (Hidalgo, Torres \& Llanos, 2014, p. 93).
\end{abstract}

En ese sentido, el Museo cumplió un papel activo y propositivo, como se evidenció en el acontecimiento de la demolición de los silos de los antiguos Instituto Nacional Agropecuario e Instituto de Mercadeo Agropecuario, elementos patrimoniales ubicados al norte de Tunja y parte de la colección digital del Cibermuseo. Este acontecimiento puso de manifiesto que deben existir vínculos entre las personas, los espacios públicos y los bienes comunes, pero además, dejó en evidencia la necesidad de crear escenarios para visibilizar dichos vínculos. 
El presente artículo desarrolla el cuarto objetivo específico del proyecto, que busca "optimizar la interacción con los visitantes mediante la evaluación de las herramientas TIC y los ejercicios propuestos". Para ello, presenta una elaboración teórica de las categorías de investigación abordadas y traza una ruta conceptual y metodológica para una posterior etapa, en aras de implementar mejoras que consigan posicionar el sitio web y lograr una mayor participación de la comunidad. Toda la información recopilada durante el proyecto ha sido empleada como insumo para el análisis. Cabe aclarar que se maneja un enfoque en la comunicación, el diseño y la museología, para emitir recomendaciones respecto al artefacto del museo virtual, es decir, el sitio web sobre el cual se soporta.

\section{LOS MUSEOS, SU GESTIÓN, SU PÚBLICO Y LA COMUNICACIÓN. CONTEX- TUALIZACIÓN TEÓRICA}

El museo tiene una larga tradición en la historia de la humanidad, aunque a través de los años el concepto se ha transformado de forma radical: desde templos sagrados hasta el control por parte de las comunidades de sus actividades y su gestión. Ya en el siglo III a. C. se construyó el Museion de Alejandría, compuesto por el mausoleo de Alejandro, la célebre Biblioteca y un templo a las musas. 'Museo' tiene sus orígenes etimológicos, precisamente, en el griego museion, "casa de las musas", significado que conservó en el latín museum. El término cayó en desuso durante la Edad Media pero en el Renacimiento fue retomado por Cosme el Viejo, al tiempo que los Medici nombraban un conservador al frente de sus colecciones. En el siglo XIX el uso de la palabra se extendió para las colecciones universales de antropología, arqueología y cualquier otra especialidad (Lorente, 2013) y las actividades de clasificación y conservación se hicieron comunes para las instituciones museológicas. Asimismo, debido a la curiosidad que generaban era permitida la visita del público, pero siempre con gran cautela: no tocar, no acercarse demasiado a los objetos y tener cuidado. El museo nació entonces con el objetivo de coleccionar, por encima de transmitir un mensaje a un público.

Hoy, esa finalidad se ha revertido. En general, se acepta que los museos se deben a su comunidad y deben pensarse y planearse a partir de ella. "Los museos, por tanto, tienen el reto de redefinir su función, sustituyendo el coleccionar, preservar y exponer, por objetivos más reales centrados en la comunicación con el público" (Pérez, 2004, p. 45). 
Un cambio en la manera de entender al público visitante. Si inicialmente este era el destinatario pasivo del discurso expositivo en relación con el cual establecía unilateralmente lo que debía saber acerca de lo que se exponía, hoy existe una clara intención, por parte de los museos más sensibilizados, de oír su voz para favorecer su interacción con el mensaje expositivo, en firme creencia de que sin esta implicación no se produce la comunicación. Este ideal responde a una configuración del visitante como sujeto activo, parte integrante de la exposición misma, sin el cual no habría exposición y que, en su interactuación con la misma, le da su forma y contenido definitivo. (García, 1999, p. 7).

Los museos están de acuerdo en que las personas son su principal preocupación, pues es por y para ellas que se estudia y conserva el patrimonio. No es casual que las palabras 'sociedad', 'público' y 'pueblos' aparezcan de forma protagónica en la definición del Código Deontológico del Consejo Internacional de Museos (ICOM):

Un museo es una institución permanente, sin fines de lucro y al servicio de la sociedad y su desarrollo, que es accesible al público y acopia, conserva, investiga, difunde y expone el patrimonio material e inmaterial de los pueblos y su entorno para que sea estudiado, eduque y deleite (2013, p. 15).

El ICOM afirma, además, que "los museos trabajan en estrecha cooperación con las comunidades de las que provienen las colecciones, así como con las comunidades a las que prestan servicios" (2013, p. 10). Bien afirmaba hace 20 años Stephen Weil (1997) que los museos deben modificar su actitud de supremacía sobre el visitante por una de servicio, de modo que el público tenga el control de las actividades y la gestión de la institución. Por ello, "un buen museo atrae, entretiene, despierta la curiosidad y sugiere preguntas, promoviendo así el aprendizaje" (Fernández \& Fernández, 1999, p. 25).

Es por esta visión contemporánea-ampliamente extendida y aceptada-que para optimizar la interacción con los visitantes es preciso comprender: 1) que cualquier actividad implica pensar en la institucionalidad del museo y las particularidades de su gestión; 2) que la relación entre los museos y su público implica reflexionar y planear los mensajes y las relaciones comunicativas; 3 ) que los museos cuentan con una amplia rama de medios y estrategias para comunicar, y entre estas, la exposición es el medio de comunicación por excelencia; 4) que el diseño es una herramienta que permite proyectar tanto los mensajes de la exposición como la interacción entre los museos y su público. A continuación se realiza una contextualización teórica de cada uno de estos conceptos. 


\section{El museo y su gestión}

Como la institución organizada y permanente que es, el museo -aunque este sea virtual- requiere una gestión planeada hacia el liderazgo, que facilite la toma de decisiones conducentes al cumplimiento de una misión. En ese sentido, la misión dirige la atención hacia las razones profundas de la existencia de tal institución y fundamenta cualquier línea de actuación o desarrollo posterior. La gestión del museo cumple, principalmente, cinco funciones: inspirar (con sentido de la misión del museo); comunicar (el mandato); dirigir (los esfuerzos hacia la consecución de las metas); controlar (la consecución de objetivos); y evaluar (el cumplimiento de las funciones del museo), (Lord \& Lord, 2008).

Pensar la gestión del museo "es de gran eficacia tanto cuando se aplica a proyectos importantes como a otros sencillos y de menor complejidad, puesto que permite asegurar una asistencia técnica y práctica que comienza desde la definición de los objetivos hasta la puesta en funcionamiento" (Hernández, 1998, p. 117). Así, es posible organizar las actividades y los equipos de trabajo de modo tal que los proyectos sean planeados y ejecutados "por diversos especialistas o un equipo interdisciplinar integrado por museólogos, arquitectos, técnicos, economistas y diseñadores que colaboren estrechamente" (Hernández, 1998, p. 118).

\section{La comunicación}

La comunicación da forma al museo en la medida que este se define en la manera de interactuar e implicar a sus visitantes. Por ello, planear el museo o una de sus actividades, y particularmente aquellas dirigidas a su público, implica planear los mensajes a transmitir, pensar cómo se dará la comunicación. El primer paso es la comprensión de los interlocutores.

La cultura, en el sentido objetivo de clave (o de código), es la condición de inteligibilidad de los sistemas concretos de significación que organiza y a los que permanece irreductiblemente (como la lengua al habla), mientras que la cultura, en el sentido de competencia, no es otra cosa que la cultura (en sentido objetivo) interiorizada y convertida en una capacidad permanente y generalizada para descifrar los objetos y los comportamientos culturales mediante la utilización del código según el cual están cifrados (Bourdieu, 2003, p. 117). 
Un museo debe entonces "tener al público en mente y configurar con rigor: ¿qué queremos contar?, ¿cómo lo vamos a contar?, ¿qué esperamos conseguir con lo que contamos?" (Fernández \& Fernández, 1999, p. 26), pues la comunicación y articulación de un mensaje es la forma de llegar a su público. A su vez, “la exposición es la herramienta más importante con que cuenta el museólogo para lograr el acercamiento y el diálogo con la comunidad" (Fernández \& Fernández, p. 9).

El museo ha dejado de ser una edificación que almacena, estudia e investiga objetos, para ser un emisor que se plantea objetivos con respecto a su comunidad y crea contenidos a partir de su colección,

\section{Ya no se expone casi todo, sino aquello que es coherente y necesario; los criterios asociativos ya no son solamente sistemáticos, taxonómicos o clasificatorios; las piezas se van a asociar y ordenar en función de referencias nuevas, teniendo en cuenta sus diversos significados culturales, económicos, religiosos, etc. (García, 1999, p. 44).}

“En el futuro sería deseable que la respuesta a ¿qué vamos a contar en la exposición?, orientara la investigación en el museo, rectificando el camino inverso seguido hasta ahora" (García, 1999, p. 9). Igualmente, el análisis de las necesidades de las personas debería orientar la exposición, en lugar de que esta fuera determinada por los objetos de la colección.

Hoy en día aceptamos como un hecho que el museo es un sistema complejo de comunicación donde los objetos que se presentan, la arquitectura, las exposiciones, los programas y los medios de edición, difusión y propaganda, actúan de forma interrelacionada y deben, por lo tanto, articularse adecuadamente (Franch, 2001). En tal contexto, la exposición se constituye en el mejor medio para entregar mensajes con fines específicos y ha de ser siempre el motivo de entrada al museo.

\section{La exposición es el medio de comunicación del museo}

Crear exposiciones, ya sean permanentes o temporales, precisa que el museo particularice en un público objetivo para que el lenguaje y los elementos del mensaje sean apropiados y pertinentes. La exposición es el "conjunto de objetos (bienes materiales) e ideas (bienes inmateriales) exhibidos a un público específico, particular o general, por ser dignos de mostrarse y cuya exhibición persigue un fin determinado" (López, 1993, p. 11). También es "el resultado del proceso evolutivo e interactivo entre los 
dos referentes de la propia exposición y que esta misma comunica: los objetos y el público" (García, 1999, p. 5). Su esencia es una comunicación visual en que el valor de la imagen, el apoyo de la autenticidad del objeto y el testimonio indiscutible del documento, establecen una comunicación directa y original con el producto del hombre (López, 1993, p. 12).

\section{La importancia del diseño}

El diseño es un elemento esencial para el éxito de una exposición. Si en teoría existen muchos criterios y formas de diseñar una exposición, en la práctica lo que condiciona los resultados positivos es la capacidad y la habilidad del diseñador para guiar y atraer la atención del público, de manera que este reciba mejor el mensaje (Fernández y Fernández, 1999).

El diseño es capaz de proyectar las cualidades y características del mensaje visual para crear un punto de encuentro efectivo entre los objetivos del emisor y el público. Justamente, así se define el esquema ontológico del diseño: por una parte, está al usuario (agente social) que desea cumplir una acción; de otro lado, una tarea que él mismo quiere ejecutar; y por último, un utensilio o artefacto del que necesita el agente para llevar a término la acción. ¿Cómo se conectan? A través de la interfase, que no es un objeto sino un espacio donde se articula la interacción entre el cuerpo humano, la herramienta y el objeto de acción (Bonsiepe, 1999).

Al final, el museo virtual debe ser una plataforma invisible,

(...) en los nuevos medios, la tecnología está demasiado presente. Y esa omnipresencia en lugar de alumbrar, deslumbra. Y ese deslumbramiento nos impide una utilización más eficaz de la misma al servicio de la comunicación, de la narrativa hipermedia. Presos de esa exaltación tecnológica, colocamos pantallas por doquier, como esas personas que compran libros simulados para llenar estanterías de salón, (Moreno, 2007, p. 220).

El diseño hace referencia a la innovación. El acto proyectual trae al mundo algo nuevo (...) Está referido al cuerpo y al espacio, sobre todo el espacio visual (...) Se dirige hacia la interacción entre el usuario y el artefacto. El dominio del diseño es el dominio de la interfase", (Bonsiepe, 1999, p. 21). 
"El Cibermuseo, un medio para reconocer el patrimonio urbano difuso de Tunja", involucró una investigación de corte descriptivo longitudinal, desarrollada desde un enfoque cualitativo en que mediante instrumentos de análisis de contenido se evaluaron los mensajes y las estadísticas producto de la interacción. Esta información, consignada por los visitantes del sitio www.cibermutua.co, fue medida cuantitativamente para conocer las características de esa interacción. Asimismo, un propósito del proyecto fue reunir datos cualitativos, por ejemplo, características de los mensajes, tipos de apropiación, reconocimiento e identificación de los elementos patrimoniales, criterios comunes y propuestas derivadas de la experiencia.

El proyecto abarcó cuatro etapas. En la primera, el equipo de trabajo examinó bienes y manifestaciones culturales en condición de olvido y abandono pero con un carácter patrimonial y entre tal conjunto, seleccionó ocho elementos para ser expuestos en el Museo. En la segunda fase se diseñaron los ejercicios, las simulaciones y los modelados con base en las TIC, incluyendo actividades pedagógicas interactivas. En un tercer momento tuvo lugar la interacción con los visitantes a través de espacios de diálogo, talleres y redes sociales en que se registraron sus comentarios, interrogantes, solicitudes o desacuerdos alrededor de los elementos presentados y la manera como se expusieron y comunicaron. La información fue recogida por medio de encuestas y herramientas propias de las plataformas digitales, tales como Google Analytics y estadísticas de Facebook. Por último, los datos obtenidos fueron consolidados y analizados para generar un reporte de estos. Los resultados se analizaron a partir de tres indicadores: ¿qué opinaron los visitantes respecto a los elementos del patrimonio urbano difuso?, ¿qué efectividad tuvo Mutua en su difusión? y ¿cómo se verificaron las dinámicas comunicativas en la interacción realizada?

Una vez cumplidas todas las etapas, el proyecto se planteó la optimización indicada en el ya referido cuarto objetivo específico. Para ello, se realizó un análisis a partir de datos cualitativos y cuantitativos. Como primera medida, se evaluaron las opiniones recogidas a través de la herramienta de recopilación de comentarios del sitio web y de los formularios de Google Drive diligenciados en el marco de los talleres efectuados con el fin de incrementar las interacciones de los usuarios, dada la intermitencia de visitas espontáneas y la pertinencia de reforzarlas. De igual manera, fueron analizados los datos estadísticos cuantitativos de visitas al sitio web, obtenidos por medio de la herramienta de Google Analytics. A continuación se presenta una evaluación global y se aportan las recomendaciones con miras a la implementación de dicha optimización. 


\section{RESULTADOS Y ANÁLISIS DE LA INFORMACIÓN}

\section{Análisis de opiniones}

En la Tabla 1 se registran distintas opiniones de los visitantes del sitio web. Aparecen tanto aciertos como desaciertos y se ha ordenado por reiteración. Las opiniones son interpretaciones, no corresponden a textos literales.

\section{PROYECTO}

Aciertos Puedo conocer cosas que no sabía que existían y aprende su historia.

Los lugares son importantes por lo que tienen para contar.

El Museo realiza un buen trabajo social.

Me antojé.

Es un buen inicio.

Podemos acceder a los lugares solo con una conexión a internet.

Interesante para quien no conoce la ciudad.

- Había visto algunos de los elementos pero no conocía su historia.

\begin{tabular}{l|l} 
Neutros & Había visto algunos de los elementos pero no conocía su historia. \\
\hline Desaciertos & $\cdot$ Deberían hacerle mayor difusión.
\end{tabular}

DISPOSICIÓN DE LOS CONTENIDOS

Aciertos Muy buena información y redacción.

Desaciertos Los textos son muy largos y densos, deberían ser más concretos. Las descripciones deberían acompañarse de imágenes, videos, mapas e ilustraciones.

La gráfica debería ser más llamativa.

Mala distribución de los contenidos.

No hay referencias de la información.

Es necesario mejorar la diagramación.

Se requiere mucho tiempo para visitar la web pues la información es extensa.

Es necesario mejorar la ortografía. 


\begin{tabular}{|c|c|}
\hline \multirow[b]{2}{*}{ Aciertos } & DISEÑO \\
\hline & 'Lindo sitio. \\
\hline \multirow[t]{2}{*}{ Desaciertos } & $\begin{array}{l}\text {-Sería bueno tener más imágenes, más dinamismo, más } \\
\text { interactividad y ser más atractivo. } \\
\text { - Es aburrido, feo, cansón y tedioso. } \\
\text { - Me gustaría encontrar colores más vivos, pues los opacos cansan. } \\
\text { - Hay enlaces que no funcionan. } \\
\text { - Los íconos no llaman la atención y no parecen enlaces. } \\
\text { - Hay secciones vacías. }\end{array}$ \\
\hline & ACTIVIDADES PEDAGÓGICAS \\
\hline Aciertos & $\begin{array}{l}\text { - Los juegos son adecuados. } \\
\text { Las visitas virtuales y los mapas son muy interesantes. }\end{array}$ \\
\hline
\end{tabular}

Desaciertos Es necesario pasar a la acción, por ejemplo hacer celebraciones o enseñar en colegios.

Tabla 1. Opiniones de visitantes del sitio web. Fuente: elaboración propia a partir de encuestas.

Recomendación específica: las opiniones no permiten inferir que el sitio web, sus contenidos, su diseño o las actividades pedagógicas sean de buena o mala condición. Otros indicadores como el tiempo o la cantidad de visitas podrían brindar más información, pero tampoco pueden tomarse como datos inequívocos. Más bien, opiniones y estadísticas, junto con los objetivos estratégicos del museo, su misión y los sentimientos de los usuarios, deben trazar la ruta de acciones a seguir. 
Sitio web (cibermutua.co). Análisis de Google Analytics

Datos del 31 de mayo de 2015 al 31 de agosto de 2016

\begin{tabular}{|c|c|c|c|}
\hline \multicolumn{2}{|l|}{ VISITAS } & \multicolumn{2}{|l|}{ Navegador } \\
\hline Sesiones & 6.953 & Chrome & $81,2 \%$ \\
\hline Usuarios & 5.772 & Firefox & $9,4 \%$ \\
\hline Nro. de visitas a páginas & 23.449 & \multicolumn{2}{|l|}{ Sistema operativo } \\
\hline Páginas vistas en cada sesión & 3,37 & Macintosh & $46 \%$ \\
\hline Duración media de la sesión & $00: 04: 25$ & Windows & $38,9 \%$ \\
\hline Porcentaje de rebote & $68,1 \%$ & Android & $8,3 \%$ \\
\hline$\%$ de nuevas sesiones & $83 \%$ & $\mathrm{iOS}$ & $2,6 \%$ \\
\hline \multicolumn{2}{|l|}{ IDIOMA } & \multicolumn{2}{|l|}{ Proveedor de servicios } \\
\hline Español & $45,3 \%$ & Telmex Colombia & $12,1 \%$ \\
\hline No identificado & $41,6 \%$ & Universidad de Boyacá & $8,9 \%$ \\
\hline Inglés & $11,7 \%$ & \multicolumn{2}{|c|}{ Periodo con más visitas } \\
\hline Otros & $1,4 \%$ & \multicolumn{2}{|l|}{ Junio - julio de 2015} \\
\hline \multicolumn{2}{|l|}{ PAís } & \multicolumn{2}{|c|}{ Días con mayor número de visitas } \\
\hline Colombia & $41,2 \%$ & 19 de julio 2015 & 117 \\
\hline Estados Unidos & $13,7 \%$ & 13 de julio 2015 & 103 \\
\hline Rusia & $5,6 \%$ & 25 de julio 2015 & 102 \\
\hline \multicolumn{2}{|l|}{ CIUDAD } & & \\
\hline Tunja & $19,5 \%$ & & \\
\hline Bogotá & $16 \%$ & & \\
\hline
\end{tabular}

Tabla 2. Análisis cuantitativo de interacción de usuarios con el sitio web. Fuente: elaboración propia a partir de los datos recogidos a través de Google Analytics.

\section{Análisis de interacciones}

Recomendación específica: los datos deben ser analizados con lupa, estableciendo relaciones directas con la realidad y apelando al sentido común. Por ejemplo, a partir de las visitas según el país podríamos inferir que el sitio es de interés para la población rusa $(5,6 \%)$ y estadounidense $(13,7 \%)$ y proponer como acción a futuro la traducción de los contenidos a los idiomas oficiales de esos territorios. Sin embargo, 
de los dos países mencionados proviene la mayor cantidad de tráfico "spam", y dado que el contenido del sitio web en su mayoría es de interés local, es muy probable que efectivamente solo sea "spam", por lo que la acción realmente debería ser mejorar las condiciones de seguridad para evitar esa problemática.

\section{CONCLUSIONES Y RECOMENDACIONES PARA LA OPTIMIZACIÓN}

\section{Optimización desde el proyecto: misión y objetivos de un museo}

El Cibermuseo es un proyecto de investigación planteado a través del método científico y la investigación cualitativa, lo cual, para la recolección de datos, resulta apropiado y se demuestra en los resultados satisfactorios y de gran calidad en cuanto a la construcción de los elementos patrimoniales. Sin embargo, para cumplir los objetivos se requirió del desarrollo de artefactos que no respondían a esa metodología, a saber, un sitio web a través del cual los visitantes interactuarían con las colecciones y las investigaciones acerca de las mismas. Podríamos decir entonces que el proyecto debería abarcar tres grandes subproyectos:

1. Reconocimiento, catalogación e investigación de los elementos del patrimonio urbano difuso.

2. Diseño y desarrollo de un museo virtual, incluyendo la incorporación de la colección, la exposición y la interacción con los visitantes, así como las tareas de gestión propias de un museo.

3. Análisis de la interacción de los visitantes con el museo y evaluación de la apropiación de los elementos patrimoniales que constituyen la colección.

Lo anterior se plantea con el fin de que cada subproyecto pueda usar las metodologías más pertinentes para su propia área de conocimiento. En el presente artículo se considera el subproyecto dos, en el que se aplicarían actividades para optimizar la interacción con los visitantes, sin dejar de reconocer que en la práctica todo debe funcionar de manera integrada y sin olvidar tampoco que el público, la dimensión educativa y pedagógica son elementos transversales de todo museo.

Como primera medida, es fundamental reconocer que el artefacto es un museo, por lo que debería integrarse toda la tradición teórica y práctica de la museología, empezando por los mandatos y recomendaciones del ICOM. Cabría preguntarse de qué manera el Cibermuseo integra en su misión y objetivos estratégicos las funciones que debería tener. Asimismo, es pertinente revisar la normatividad nacional, en particular la establecida por el Programa de Fortalecimiento de Museos del Ministerio de Cultura, que a su vez le permitiría acceder a los recursos económicos que ofrece dicha entidad. 
En esa misma tradición teórica y práctica se diferencian conceptos como museo, exposición y fondos o archivos, para aclarar que un museo no son (todos) sus contenidos ni los objetos que posee. Sobre este particular puede referirse una opinión reiterativa de los visitantes: "Los textos son muy largos y densos, deberían ser más concretos", al considerar que el mensaje debería ser más corto. Se recomienda plantear exposiciones temáticas limitadas en la cantidad de tiempo y extensión del mensaje, con guiones museográficos y objetivos específicos definidos y diferenciados para ayudar a mantener el interés en el sitio, los cuales, al mismo tiempo, podrían convertirse en un escenario propicio para hacer promoción. En conclusión, hacer uso de las recomendaciones aportadas por la gestión de museos podría ayudar a dinamizarlo, y finalmente, lograr mayor interacción.

De otro lado, es necesario elegir una metodología adecuada para la construcción de un artefacto resultado de un proceso de diseño (elaborar un brief, identificar las restricciones de tiempo y recursos y con ello determinar su alcance). Se trata de un proceso alterno al método científico (solo en cuanto al diseño). A continuación se explica cómo elegir dicha metodología.

\section{Optimización desde la comunicación: diseño centrado en el usuario}

Construir un museo virtual es construir un mensaje. Contrario a lo que sucede con un museo físico donde no necesariamente todo debe estar disponible al público, si el museo es completamente virtual, incluso sus fondos o los contenidos que no sean accesibles a un determinado público pueden serlo para otro. Esto implica diseñar la manera en que esos usuarios van a llegar hasta los diferentes niveles y capas de información que atiendan sus necesidades diversas. Para un museo físico este diseño estaría a cargo de un arquitecto, quien trazaría la ruta de acceso: escaleras, puertas, ascensores, pasillos, etc. para llegar hasta un elemento específico. Mientras tanto, en un museo virtual ese diseño implica comunicación, orientar al usuario en el espacio virtual y trazar las rutas de acceso a la información. Llama la atención el comentario "no hay referencias de la información", pues dichos datos sí están disponibles, solo que para el usuario no fue clara la ruta de acceso a ellos. El Cibermuseo debe determinar dónde están sus exposiciones, sus piezas icónicas, sus fondos y sus archivos, así como el espacio para el diálogo y la interacción, no sin antes cuestionarse por qué internet como medio para transmitir el mensaje.

Por otro lado, dado que el soporte del Cibermuseo es un sitio web, es recomendable plantear el proyecto de diseño y desarrollo del mensaje, la disposición de los contenidos y la interfaz visual, a través de metodologías, herramientas e instrumentos de diseño centrado en el usuario, tales como design thinking, storytelling, visual thinking, service 
design thinking, el diseño participativo o la teoría de la Difusión de las innovaciones. El propósito es reconocer las necesidades y los deseos desde los usuarios en aras de entregarles soluciones adecuadas, integrándolos durante todo el proceso de diseño, de modo que el público mismo, desde sus iniciativas, colabore en el cumplimiento de los objetivos o la misión del Cibermuseo. De tal forma se actuaría en doble vía, al ser un excelente primer paso para construir la comunidad con los primeros visitantes y entablar el diálogo. Inclusive, como se manifestó en las reuniones del equipo de trabajo, a través de propuestas totalmente innovadoras y disruptivas podría convertirse en un referente que estimule la participación y la construcción del conocimiento de forma activa.

Esta construcción de la mano con los usuarios evitaría el efecto del anonimato en los comentarios, pues no necesariamente implica que la implementación de mejoras basadas en las opiniones pueda llevar al éxito, mientras que sí lo puede conseguir el "prototipado" y testeo rápido, junto a un análisis constante desde metodologías ya existentes para ello, como son los análisis de usabilidad, si bien estos tampoco son suficientes: un sitio puede ser completamente usable y no deleitar.

La red se ha convertido en un espacio de contenidos y de historias que generan entusiasmo a través de la empatía. Los datos ocupan un segundo plano y en ese sentido el Cibermuseo tiene mucho potencial, pues el proyecto ya posee una cantidad de material capaz de generar interés en el público. Ese material producto de la investigación y la experiencia es el punto de partida para la creatividad, la imaginación, la curiosidad y la estructuración de un mensaje que deleite. Cualquier estrategia que use internet como plataforma debe procurar contenidos que generen valor en su comunidad y le sean útiles. Cabe entonces que el Cibermuseo se pregunte cómo genera valor en su comunidad.

De otra parte, internet cuenta con amplia teoría y casos prácticos referentes al marketing. Esta sería otra herramienta a la cual acudir para hacer llamativo, cautivante y cercano el Cibermuseo. De hecho, como el mismo marketing digital lo indica, ir hasta los seguidores y no quedarse esperándolos.

De todas formas, y a pesar de mucho planear, el sitio web puede ser un detonante de la interacción. Cabe entonces otra posibilidad: dejar a la deriva ciertos elementos y formular estrategias de acuerdo a ideas surgidas en la misma interacción. Por ejemplo, el comentario de un profesor de un colegio indicaba que le gustaba mucho el sitio y le gustaría entablar un diálogo más personalizado. La respuesta a esta inquietud 
puede ser el punto de partida para un proyecto nuevo de corta duración. De entrada hay interés, algo verdaderamente difícil de conseguir. ¿Qué tal dejar espacios para lo no planeado, espontáneo, improvisado, imprevisto, intuitivo, repentino, sorprendente, impensado y fortuito?

No se puede olvidar lo difícil que ha sido construir comunidad y públicos, así como el tiempo y el trabajo que esto ha conllevado, sobre todo cuando se persiguen fines educativos. Ver resultados y transformaciones toma tiempo, por lo tanto, cada comentario, cada invitación, cada pregunta, debe tomarse como un gran logro y responderse con acciones de la misma manera, haciendo sentir importantes a esas personas, continuando el diálogo e incluso resaltándolo.

\section{Optimización de aspectos visuales y tecnológicos}

En cuanto a los rasgos visuales, el Cibermuseo debe establecer una caja de herramientas de posibilidades digitales, partiendo de los elementos básicos del diseño: tipografía, color, escalas, composición, formas, brillos e imágenes, para pasar a los textos y a elementos puntuales de mayor complejidad (infografías, condiciones de accesibilidad, actividades, videos). En últimas, el diseño ha de ser invisible. En los comentarios se encuentran quejas respecto a lo malo y felicitaciones frente a lo bueno, pero el diseño no debería ser el tema de conversación, cuando el objetivo es la apropiación del patrimonio.

En cuanto a los recursos tecnológicos, el software de diseño y las plataformas web deben pensarse para transformarse de forma rápida sin requerir demasiado trabajo. Software para "prototipado" rápido como Sketch o Justinmind Prototyper y plataformas con estructuras dinámicas y sencillas como WordPress o Drupal. En todo caso, es preciso estudiar más a fondo y aprender de los referentes existentes, tanto de sitios web como de museos virtuales. Una estrategia podría ser conseguir el apoyo de profesionales con trayectoria en el medio que actualmente se dediquen al desarrollo de estos sitios, para tener así una mirada al respecto.

Por último, en cuanto a lo metodológico, el equipo de trabajo cumple un papel esencial, por lo que se deben considerar las curvas de aprendizaje de nuevas tecnologías, metodologías y herramientas entre los integrantes, así como los recursos apropiados para contratar elementos que cuenten con perfiles especializados, si así se requiere. También es necesario contar con tiempos adecuados para las distintas tareas según sus niveles de complejidad, sin descuidar la construcción colectiva, el ejercicio transdisciplinar y el diálogo de saberes. 


\section{REFERENCIAS BIBLIOGRÁFICAS}

Bonsiepe, G. (1999). Del objeto a la interfase. Buenos Aires: Infinito.

Bourdieu, P. \& Darbel, A. (2003). El amor al arte. Los museos europeos y su público. Barcelona: Paidós.

Consejo Internacional de Museos. (2013). Código de Deontología del ICOM para los museos. París: autor.

Fernández, L. \& Fernández, I. (1999). Diseño de exposiciones. Concepto instalación y montaje. Madrid: Alianza.

Franch, E. (2001). Museos y comunicación. Treinta años después. Experimenta, 36, 30-31.

García, A. (1999). La exposición, un medio de comunicación. Madrid: Akal.

Hernández, F. (1998). Manual de museología. Madrid: Síntesis.

Hidalgo, A., Torres, I. M. \& Llanos, J. A. (2014). Identificación e incorporación de elementos del patrimonio urbano difuso tunjano al Ciberecomuseo Mutua. Designa, 3(1), 92-121.

López, F. (1993). Manual de montaje de exposiciones. Bogotá: Museo Nacional de Colombia.

Lord, B. \& Lord, G. (2008). Manual de gestión de museos. Barcelona: Ariel.

Lorente, J. (2013). Manual de historia de la museología. Gijón, España: Trea.

Moreno, I. (2007). El museo interactivo. Tecnología invisible y diálogos ininterrumpidos. En M. Schultz (Coord.). El factor humano en la cibercultura (pp. 219-238). Buenos Aires: Alfagrama.

Pérez, E. (2004). ¿Quién es el público de los museos? En M. Fernández (Coord.). La voluntad de mostrar, el ingenio de ver (pp. 44-57). México: Conaculta.

Weil, S. E. (1997). The museum and the public. Museum and public, Museum Management and Curatorship, 16(13), 257-271. 